\title{
O DESENVOLVIMENTO DO TEXTO DISSERTATIVO EM CRIANÇAS DA 4ª SÉRIE
}

\author{
SÉRGIO ANTONIO DA SILVA LEITE \\ Professor do Departamento de Psicologia Educacional da Faculdade de Educação da Unicamp \\ ANA MARISA DE CAMPOS VALLIM \\ Psicopedagoga da Secretaria de Promoção Social da Prefeitura Municipal de Mojiguaçu
}

\begin{abstract}
RESUMO
Esta pesquisa analisa o desenvolvimento da habilidade de produzir textos dissertativos em crianças da $4^{\text {a }}$. série, relacionando com o contexto em que foram produzidos. Este estudo justifica-se devido à escassez de trabalhos lingüísticos na área, bem como ao alto índice de fracasso dos alunos nesta modalidade de texto. Coletou-se a produção escrita de crianças de rede pública, durante um período de três meses. $\bigcirc$ material foi analisado buscando-se identificar os operadores argumentativos, os tipos de argumentos utilizados e o estágio da capacidade argumentativa dessas crianças. O estudo sugere que a introdução do texto argumentativo nas séries iniciais do $1^{\circ}$ grau, além de proporcionar mais chances de sucesso aos alunos na produção deste tipo de texto ao término do $2^{\circ}$ grau, certamente facilitará o desenvolvimento de uma postura crítica, possibilitando aos alunos refletirem sobre a realidade social onde vivem. CRIANÇAS - ENSINO DE I ${ }^{\circ}$ GRAU - PROCESSO ENSINO-APRENDIZAGEM - ESCRITA - LEITURA LINGUAGEM
\end{abstract}

\section{ABSTRACT}

THEDEVELOPMENT OFARGUMENTATIVE TEXT BY FOURTH GRADECHILDREN. This reaserch analysed the developmental stage of fourth grade (primary school) children in ability of writting argumentative texts joint with their context. The reason of this reaserch is the lack of new studies in linguistical area and high ratio of unable students to make this kind of text. It will be showed the analysis of making text by public schools children for three months. These data were analysed trying identify argumentative operators, the kinds of arguments used and the stage of the argumentative ability of these children. The study showed that the introduction of argumentative text in first grades give them more chances of succeed, preparing these pupils in their finishing high school. This fact obviously will make easier the development of their critical point of view, helping the students to think about their living social reality.

Este trabalho foi realizado com o apoio da Fapesp. 


\section{INTRODUÇÃO}

São muito conhecidas, entre os educadores, as dificuldades das crianças na compreensão e na produção de textos dissertativos na escola, bem como os altos índices de fracasso dos vestibulandos na produção desses textos.

No entanto, a modalidade dissertativa não tem merecido muita atenção nos estudos lingüísticos, tanto do ponto de vista descritivo de sua manifestação nas diversas faixas etárias, quanto do ponto de vista explicativo dos mecanismos de seu desenvolvimento em nossa língua.

Cabe ressaltar que o termo "texto ou discurso dissertativo" parece ser utilizado mais por autores em estudos realizados em nosso meio, uma vez que na bibliografia consultada de pesquisas mais recentes sobre o assunto, nas línguas inglesa e francesa, o termo citado pelos autores é "texto ou discurso argumentativo". Desta forma, optou-se por utilizar o termo "texto dissertativo"; porém, nas citações bibliográficas, será respeitado o uso do termo utilizado pelo autor citado.

Em nossa cultura, essa modalidade de discurso costuma ser muito privilegiada e explorada na escola, mais especificamente no $2^{\circ}$ grau, visando à construção de um discurso acadêmico e científico. Portanto, o texto dissertativo, dentro dos moldes formais, é conhecido como um produto do processo de escolarização do aluno.

Segundo Martinez:

A dissertação é um tipo de discurso através do qual procedemos à reflexão sobre as coisas, onde explicitamos opiniões, e sobretudo onde a nossa intenção é fazer com que o nosso interlocutor acate as nossas opiniões e, desse modo, se ponha do nosso lado nas considerações que tecemos. (1988, p.91)

Essa intenção de persuasão, presente na linguagem discursiva, implica o esforço de uso da argumentação, ou seja, o ato de orientar o discurso no sentido de determinadas conclusões.

Como não existe neutralidade de discurso, quando o indivíduo reflete sobre algo e emite sua opinião, ele expressa os juízos de valor que quer incutir no interlocutor para persuadi-lo e conseguir adesão a seu ponto de vista.

Quanto ao ensino do discurso dissertativo na escola, Osakabe (1977, p. 52) ressalta que "o desempenho dissertativo implica o bom desempenho argumentativo"; por isso é importante considerar que a atitude reflexiva ou argumentativa deve ser ativada tanto quanto ou mais que os outros discursos trabalhados na escola de $1^{\circ}$ grau. Essa seria uma das formas de amenizar, futuramente, os altos índices de fracasso dos alunos na modalidade de texto. Isto porque o narrar e o descrever uma história ou um fato ocorrido, na realidade, são atividades lingüísticas que o indivíduo realiza desde muito cedo, implicando reconstituir um acontecimento ou captar um momento que faz parte da sua experiência. 
Não é o que ocorre no argumentar, no entanto, pois quando se comenta e se posiciona sobre algo, emitem-se julgamentos de valor sobre o objeto em discussão com o intuito de persuadir o interlocutor. Nessa tarefa, o indivíduo usa sua linguagem para "construir" ou "montar" o seu discurso, do qual dependerá o êxito de sua intenção. Isso demanda conhecimento sobre o assunto que se vai abordar e uma tomada de posição crítica diante do assunto.

Pesquisas recentes (Banks-Leite, 1996; Petroni, 1994; Golder, 1994; Lopes, 1992) têm mostrado que crianças desde 4 ou 5 anos de idade dominam a forma discursiva dissertativa oral já bem elaborada, o que Ihes garante uma comunicação satisfatória, embora longe dos moldes formais da língua escrita.

Banks-Leite (1996, p. 172) faz a seguinte afirmação, a partir de pesquisa com crianças de idade média de 5 anos: “(...) as análises empreendidas e apresentadas no capítulo anterior nos parecem suficientemente claras para afirmarmos que há uma argumentação bem elaborada em crianças da faixa etária examinada".

No mesmo sentido, Lopes apresenta as seguintes hipóteses:

Resta indagar se as crianças construiriam suas respostas escritas da mesma maneira que fizeram oralmente. Supondo que na faixa dos seis aos oito anos a criança ainda não domina plenamente a forma padrão escrita da linguagem, acreditamos que o discurso oral funcione como um apoio e também um meio de se atingir esta forma. Talvez um estudo futuro possa nos trazer uma luz sobre estas hipóteses. (1992, p. 121 )

Se tais pesquisas mostram que existem formas de dissertação oral, como atividade lingüística rotineira em crianças, por que esperar o $2^{\circ}$ grau para começar a explorá-la na modalidade escrita? Nesse sentido, este trabalho propõe demonstrar que as crianças de $4^{\mathrm{a}}$ série são capazes de construir textos escritos da mesma maneira que o fazem oralmente, emitindo definições, explicações e sustentando opiniões.

Esta pesquisa buscou analisar a habilidade de produzir textos do tipo argumentativo em crianças de 10 a II anos, que estavam na $4^{\text {a }}$ série, relacionando com o contexto em que os mesmos foram produzidos. Optou-se por analisar: os operadores lingüísticos argumentativos, os tipos de argumentos utilizados, os estágios de aquisição da capacidade argumentativa e o desenvolvimento dessa habilidade de argumentar.

Para a análise dos operadores lingüísticos argumentativos apresentados nos textos produzidos foram utilizados, como referencial teórico, os princípios da Lingüística Textual.

A Lingüística Textual teve maior desenvolvimento a partir da década de 80 e, tal como vem sendo entendida atualmente, apresenta diversas vertentes. Conforme Koch (1993, p. 14), a Lingüística Textual toma como objeto particular de investigação não mais a palavra ou a frase isolada, mas o texto, considerado a unidade básica de manifestação da linguagem, visto que o homem comunica-se por meio de textos; além disso, entende que existem diversos fenômenos lingüísticos que só podem ser explicados no interior do texto. 
Este trabalho foi elaborado, portanto, com base nos princípios da Lingüística Textual, pois esta tem como objeto de pesquisa o texto, considerando-se como seu elemento fundamental a construção do sentido. Atribui-se um papel secundário aos aspectos gramático-formais, tão priorizados pela escola tradicional.

A Lingüística Textual propõe uma nova concepção de texto, definindo-o da seguinte maneira:

Texto é uma unidade lingüística concreta (perceptível pela visão ou audição), que é tomada pelos usuários da língua (falante, escritor/ouvinte, leitor), em uma situação de interação comunicativa reconhecível e reconhecida, independentemente da sua extensão. (Koch, 1993, p. 10)

Nessa linha de compreensão, a Coordenadoria de Estudos e Normas Pedagógicas da Secretaria de Educação do Estado de São Paulo - CENP - considera texto "...todo trecho falado ou escrito que constitui um todo unificado e coerente dentro de uma determinada situação discursiva" (1992, p. 18).

Quanto à análise dos aspectos referentes à argumentação, ou seja, os tipos dos argumentos, os estágios de aquisição da capacidade argumentativa e o desenvolvimento da habilidade de argumentar das crianças, utilizaram-se como referencial teórico os estudos realizados por psicólogos e psicolingüistas integrantes do Laboratoire de Psychologie du Langage da Universidade de Poitiers e da Universidade de Genebra. Esta linha teórica interessa-se pelas operações lógicas entendidas como operações do pensamento, expressas e manifestas pelas atividades discursivas. $\bigcirc$ estudo da argumentação é de grande interesse dessa linha teórica, uma vez que argumentar é uma das facetas do raciocínio, assim como o provar e o calcular (Grize apud Banks-Leite, 1996, p. 53).

Conforme Banks-Leite, tais estudos concebem o discurso argumentativo da seguinte maneira:

É um tipo de discurso finalizado que se produz em situação dialógica, que tem o objetivo de agir sobre um interlocutor, tentando modificar suas atitudes, suas opiniões e mesmo seu comportamento, com a ajuda de esquematizações adequadas, e estas esquematizações se constroem em função da finalidade do locutor e da representação que este tem de seu auditório ou ouvinte. $(1996$, p. 53)

A esquematização deve ser entendida como a construção de uma representação discursiva. Banks-Leite, para maior compreensão do termo, explica:

... pode-se supor que em um determinado momento e situação, um locutor A dirige um discurso em língua natural a B (auditório ou ouvinte - real ou virtual), na tentativa de levar B a adotar uma certa atitude ou comportamento. Nesse sentido, A propõe uma esquematização de forma tal que $\mathrm{B}$ possa reconstruí-la. Esse termo remete, simultaneamente, à idéia de processo de produção de uma atividade discursiva, mas também a um resultado que seria um "esquema" da situação. (1996, p. 53, grifos e aspas do original) 
Segundo a autora (1996, p. 60), para os psicólogos de Poitiers, o discurso argumentativo concebido como a construção, por um locutor, de uma esquematização, com o objetivo de modificar a representação de um interlocutor sobre um objeto determinado, constitui uma conduta lingüística que faz intervir operações, tais como:

- operações de sustentação: para ter possibilidade de convencer um auditório, o locutor deve sustentar, apoiar suas afirmações;

- operações de construção e de interpretação do referente: uma das características deste discurso reside na possibilidade ou necessidade de reconstrução dos objetos dos quais ele trata;

- operações de implicação do locutor. considerando-se que o locutor visa convencer seu parceiro, ele é levado a definir o lugar deste e o seu em relação às posições tomadas.

A análise dos textos dissertativos desta pesquisa foi baseada em tais operações da conduta lingüística.

\section{MÉTODO}

método empregado neste trabalho fundamenta-se na abordagem qualitativa dos fenômenos educacionais, com referência ao discurso argumentativo escrito. A pesquisa qualitativa em educação, segundo os autores Bogdan e Biklen (apud Ludke, André, 1986, p. 13), "envolve a obtenção de dados descritivos, obtidos no contato direto do pesquisador com a situação estudada, enfatiza mais o processo do que o produto e se preocupa em retratar a perspectiva dos participantes".

\section{Sujeitos}

Os dados foram coletados com um grupo de 17 alunos de uma classe do Programa Atendimento Integral à Criança e ao Adolescente - AICA' -, desenvolvido pela Prefeitura Municipal de Mojiguaçu, na qual um dos pesquisadores lecionava.

A maioria do grupo era oriunda de famílias de trabalhadores braçais e freqüentava a $4^{\text {a }}$ série da EEPG "Benedita Nair X. Vedovello". O núcleo do AICA era do Jardim Santa Terezinha.

1. Este programa desenvolve atividades de reforço escolar e recreação com crianças que estejam freqüentando da |à à $4^{\mathrm{a}}$ série do $1^{\circ}$ grau em escolas públicas; funciona em horário alternado ao da escola onde as crianças estudam. As salas de aula localizam-se em prédios próprios ou em creches, geralmente localizadas em bairros da periferia da cidade. Atende, atualmente, cerca de 750 crianças carentes. 
Foram coletados dados relacionados com a produção escrita de crianças em sala de aula, como produto das interações professor-aluno, adulto (profissionais)-aluno e alunoaluno.

\section{Descrição do processo de produção escrita}

O planejamento das atividades visando à produção de textos foi baseado na proposta interacionista de aquisição da linguagem. Tal proposta muito tem contribuído com os educadores ao privilegiar a interação da criança com o adulto educador. Conforme Lemos (1986, p. 245), é por meio do processo dialógico que a criança pode "conceber a si e ao outro como sujeitos" na construção de sua linguagem.

A criança, ao mesmo tempo em que vai compreendendo as características próprias do seu discurso argumentativo oral, vai também compreendendo e desenvolvendo as do tipo argumentativo escrito. Acrescente-se, ainda, que a linguagem escrita não é considerada como a representação direta da linguagem oral, mas sim uma modalidade de linguagem que tem características próprias.

Foram realizados três processos de produção escrita; cada um foi desenvolvido em sessões distribuídas, em média, durante 30 dias; todo o processo foi realizado durante o período de setembro a novembro. Cada processo de produção escrita foi desenvolvido de acordo com um procedimento básico, cujas etapas estão descritas abaixo.

\section{Escolha do tema}

Todas as produções escritas tiveram como ponto de partida o diálogo grupal sobre fatos ocorridos na comunidade durante a Hora da Novidade. Naquele momento, as crianças eram solicitadas a relatar fatos do seu cotidiano. $O$ professor atuava problematizando e questionando as colocações apresentadas. Desenvolvia-se, então, um período de intensa relação dialógica que terminava quando o professor perguntava se todos gostariam de estudar e escrever sobre aquele assunto. Mediante o consenso grupal, planejaram-se as atividades seguintes.

Os temas escolhidos pelas crianças foram:

- I a produção escrita: O PROBLEMA DOS MENINOS DE RUA;

- $2^{a}$ produção escrita: O ALCOOLISMO;

- $3^{\mathrm{a}}$ produção escrita: A VIOLÊNCIA.

\section{Coleta de informações sobre o tema}

Foram realizadas atividades visando à obtenção de informações sobre o tema. A primeira produção envolveu a participação dos alunos nas atividades da $I^{\text {a }}$ Semana de 
Cidadania de Mojiguaçu, quando assistiram à exposição de fotos e palestras. Posteriormente, leram e discutiram o livro Amarelinho, de Ganymédes José (Ed. Moderna). Cada atividade era centrada no processo dialógico entre as crianças, que eram incentivadas pela professora.

Na segunda produção, desenvolveram-se atividades de leitura de textos selecionados sobre o alcoolismo, enfocando seus danos individuais e sociais. As leituras eram precedidas de momentos de discussão, troca de experiências e opiniões etc.

A terceira produção envolveu atividades de pesquisa de material sobre o tema violência nos meios de comunicação, tentando identificar suas possíveis causas e conseqüências. Além disso, foram lidos e discutidos artigos publicados em jornais, além da realização de uma entrevista planejada e desenvolvida coletivamente, na sala de aula, com um policial e uma delegada de polícia. Tal atividade foi escolhida pelas crianças. Essa fase terminou com mais leitura de textos dissertativos, publicados em jornais, em que os alunos eram incentivados a identificar a opinião do autor sobre o assunto em questão.

\section{Momento de síntese sobre o tema}

A fase de coleta de informações era concluída por uma atividade entre a professora e os alunos, quando se tentava uma síntese sobre o tema, incentivando-se o posicionamento de cada um sobre o assunto. Novamente, era pela relação dialógica que a professora atuava.

\section{Elaboração do texto}

Cada criança elaborava o seu texto individualmente, a partir de um título sugerido coletivamente pelo grupo.

\section{Reescrita do texto}

Após a leitura pela professora, os textos eram devolvidos às crianças com comentários escritos e apresentados por ela. A criança tinha, então, a oportunidade de reescrever o texto (era incentivada, mas não obrigada), após relê-lo e refletir sobre os comentários da professora. Tais comentários eram desenvolvidos no sentido de incentivar os alunos a aprofundar mais seus posicionamentos críticos, sustentados nos argumentos desenvolvidos.

\section{Socialização dos textos}

Para finalizar o processo, os textos eram reunidos em um "livro" com a função de informar as crianças de outras classes sobre o tema estudado assim como divulgar as opiniões emitidas pelos seus autores. A elaboração do "livro" foi combinada no início do processo, sendo que uma cópia do mesmo era enviada para as outras classes.

Deve-se ressaltar que as crianças demonstraram uma grande motivação para participação em cada fase, garantida, provavelmente, pelo fato de o tema estar relacionado 
com questões do cotidiano dos sujeitos, pela relação dialógica constante em cada atividade e pela funcionalidade da escrita - havia um "para quê" e "para quem" estar escrevendo.

\section{ANÁLISE E RESULTADOS}

$\mathrm{Na}$ análise dos enunciados argumentativos, buscou-se identificar a maneira pela qual a argumentação apareceu nos textos produzidos pelas crianças. Foram desenvolvidos quatro níveis de análise.

Buscou-se, no primeiro nível de análise, identificar e/ou caracterizar, nos textos produzidos, os operadores argumentativos; no segundo nível, os tipos de argumentos utilizados; no terceiro nível, o estágio de aquisição da capacidade argumentativa; finalmente, no quarto nível, o desenvolvimento da habilidade de produzir textos dissertativos argumentativos de algumas crianças.

Nos três primeiros níveis de análise, foram utilizados os textos da terceira produção escrita, num total de 17 textos, quando se tratou da temática violência. A opção por esta produção escrita justifica-se pelo fato de os alunos terem demonstrado, por meio de seus textos, uma melhor compreensão sobre o assunto em questão, uma vez que já haviam estudado, nas duas primeiras produções, outros problemas sociais do cotidiano em que vivem.

\section{Os operadores lingüísticos argumentativos}

Segundo a Lingüística Textual, o termo operador argumentativo refere-se a certos elementos da gramática de uma língua que têm por função indicar a força argumentativa dos enunciados no sentido de determinadas conclusões, com exclusão de outras.

Conforme Koch (1987), é necessário explicitar que na Lingüística Textual empregase o termo operador argumentativo ou operador discursivo para se referir às partículas que a gramática tradicional classifica como conjunção ou conectivo. Além de conjunções ou conectivos, também certas palavras que não se enquadram nas dez classes gramaticais tradicionais são nomeadas como operadores. Tanto as conjunções quanto essas palavras sem classificação especial são marcas lingüísticas determinantes no processo de enunciação.

Como ponto de partida, foram selecionados, dentre os 17 textos produzidos na terceira produção (tema: violência), alguns enunciados retirados dos textos, nos quais se buscou caracterizar o fenômeno da argumentação. Poderá ocorrer que tais enunciados não sejam analisados em sua totalidade ou que um mesmo enunciado seja objeto de mais de uma análise dependendo do aspecto que está sendo tratado.

O Anexo I apresenta, na íntegra, os 17 textos produzidos, com grifos que orientam o leitor quanto a ocorrências dos aspectos analisados. Os textos foram transcritos respeitando-se a organização textual de cada aluno, bem como o padrão ortográfico. 
Os operadores argumentativos identificados nos textos das crianças foram:

- MAS: é utilizado para contrapor ao enunciado anterior, no qual são apresentadas conclusões contrárias, sendo que deverá prevalecer o enunciado introduzido pelo mesmo operador; por isso é conhecido como operador de contra-argumentação.

Este operador apareceu em três textos, dos quais observaremos um deles:

Antigamente no Brasil não existia muitas violência mas hoje em 1995 existe muitas violencias. Por exemplo drogas, brigas, morte etc... E também não acaba isto, mas diminuir sim. Mas como as policias vem aguentar isto? A cadeia não resorve. Se ficar soltos mata não tem condições. (Texto I)

- POR EXEMPLO: este operador é usado para exemplificar a posição assumida pelo locutor no enunciado anterior. Ele apareceu quatro vezes em diferentes textos e as crianças não apresentaram dificuldades no seu uso, como mostra o enunciado anterior.

- PORQUE, POR CAUSA, COM (usado no sentido do operador devido): estes operadores têm a função de introduzir uma explicação ou justificação ao enunciado anterior. O operador PORQUE foi o mais utilizado pelas crianças, enquanto o POR CAUSA apareceu em quatro textos e o COM em apenas um texto.

Muitos presos na delegacia agride os outros por que não obedeceu o chefe da cadeia la na cadeia cada um tem um religião. (Texto 2)

Muitas pessoas morrem, por causa das Brigas. (Texto 16)

A número de violência em nosso município vem aumentando cada vez mais com as rebeliões que acontecem nas grandes cidades. (Texto 5)

- só (usado no sentido de APENAS): este operador orienta a argumentação para a negação da totalidade e apareceu em dois textos.

A violência na rua é muito comum em todas as cidades $\underline{\text { enão é só criança que briga é também }}$ adultos, $(. .$.

A violência nas casas é que a mãe bate nos filhos só por causa que os filhos não querem sair da para trabalhar, e também existe outro tipo é o marido bater na mulher na mulher por causa da bebida ou das drogas. (Texto 8 )

- E, NÃO É SÓ..., É TAMBÉM, TAMBÉM, NEM: estes operadores são utilizados para somar argumentos a favor de uma mesma conclusão. $O$ operador $E$ apareceu em sete textos, enquanto os demais apareceram em dois textos, sem dúvida porque o operador $\mathrm{E}$ é mais comum na linguagem falada das crianças. Ver exemplo anterior e o seguinte: Hoje policias não estão nem conseguindo pegar ladrões (Texto 17). 
- POR ISSO, DESDE ENTÃO, NISSO (usado no sentido de LOGO): introduz uma conclusão relativa a argumentos apresentados em enunciados anteriores. Ambos os operadores apareceram somente em um texto, mostrando o pouco uso desta operação pelas crianças e que pode ser estimulada por um ensino mais sistematizado desses operadores.

...O que acontece é que maridos não tem muito amor em sua família.

E por isso quando tem muito problema em sua casa na rua ou em qualquer outro lugar.

Desde então bebe muito e sua família que não tem nada há vê com isso que acaba levando as conseqüências. (Texto 6)

...Porque os fugitivos vêem para as cidades do interior. E nisso nossa cidade fica com grande números de pessoas violentas. (Texto 5)

- ATÉ, ATÉ MESMO, MESMO (usado no sentido de ATÉ MESMO): estes operadores assinalam o argumento mais forte de uma escala de argumentos orientada no sentido de uma conclusão. O operador ATÉ foi utilizado em apenas um texto, e o ATÉ MESMO em dois textos.

A violência no trânsito é mais ou menos diferente, muitas pessoas bêbadas ou até sem estar bêbadas não respeitam a sinalazão ${ }^{2}$ ou as regras do trânsito Essas pessoas defiam ${ }^{3}$ ser multadas ou até mesmo pressas. (Texto 6 )

- OU: este operador argumentativo, assim como os operadores OU ENTÃO, QUER... QUER, SEJA... SEJA etc. introduzem argumentos alternativos que levam a conclusões diferentes ou opostas. Ele foi observado somente no enunciado do texto citado anteriormente.

- COMO (usado no sentido de ASSIM COMO): este tipo de operador estabelece relações de comparação entre elementos, com vistas a uma dada conclusão. Ele foi utilizado em apenas um texto, como segue abaixo: Em nosso país existe muitas violencias como em outros países. O nosso país é muito violento (Texto I I).

Em síntese, pode-se afirmar que foi bastante variada a utilização dos tipos de operadores argumentativos pelas crianças. Foram utilizados nove tipos de operações argumentativas, sendo que a mais freqüente foi PORQUE.

Cabe salientar que tais operadores devem ser estimulados tanto na oralidade como na língua escrita, uma vez que proporcionam à criança trabalhar os conceitos, ou, mais especificamente, organizar seu texto com mais de um argumento, relacionando esses argumentos com o uso de diferentes operadores.

2. Provavelmente o que a criança tentou escrever foi a palavra sinalização.

3. Ocorre a grafia incorreta do verbo dever (deviam). 


\section{Tipos de argumentos}

Os tipos de argumentos, ou seja, a natureza dos argumentos identificados nos textos variaram de acordo com os modos factual, axiológico e prescritivo, sugeridos por Golder (1993, p. 365). A autora partiu da análise de diálogos orais de crianças de 4 a 9 anos e constatou que, cada vez que a criança toma a palavra no diálogo, ela produz um tipo de argumentação que se pode desenvolver de um modo factual, axiológico ou prescritivo.

Ainda conforme Golder (1993, p.365), os argumentos de natureza factual podem ser divididos em três:

- Argumento Factual Particular: refere-se a enunciados de experiências ou valores pessoais do locutor;

- Argumento Factual Geral: refere-se a enunciados de experiências ou valores mais coletivos do locutor;

- Argumento Factual Geral-Particular. refere-se a enunciados que combinam experiências ou valores particulares e coletivos.

Nesta pesquisa, considerou-se também, como argumento factual, a narração de uma história dentro do texto quando esta era utilizada pelo locutor para sustentar seu posicionamento e persuadir seu interlocutor, embora Golder não aborde tal fato em seus estudos.

Os argumentos do tipo axiológico referem-se àqueles que exprimem, mais freqüentemente, um julgamento moral do locutor.

Já os argumentos do tipo prescritivo referem-se à avaliação de uma obrigação pelo locutor.

Na presente pesquisa, tratando-se de textos escritos, pode-se observar que os tipos de argumentação, geralmente, são marcados por parágrafos (quando a criança os utiliza) ou início de frases.

Quanto à presença de argumentos factuais no corpus da pesquisa, foi possível identificar somente um caso de uso de argumento factual particular, como segue:

Então não briguem porque você vai em mal caminho.

Um dia um homem bebeu pinga e queria me bater e ai eu fique quieto no meu lugar meu pai falou se alguém mexer comigo é para mim chamar ele. (Texto |4)

Este enunciado foi identificado como um argumento de natureza factual particular, uma vez que a criança conta uma história pessoal e, a partir dela, defende a idéia de que não se deve brigar, mas buscar outras formas para resolver o problema das ofensas "porque você vai em mal caminho".

Os argumentos do tipo factual geral estiveram presentes em todos os textos; destacamos a seguir alguns deles: 
A número de violência em nosso município vem aumentando cada vez mais com as rebeliões que acontecem nas grandes cidades.

Porque os fugitivos vêem para as cidades do interior. E nisso nossa cidade fica com grandes números de pessoas violentas. (Texto 5)

A violência é quando os pais brigam com os filhos, porque está com algum problema no trabalho, em casa e algum lugar.

Em nosso país existe muitas violencias como em outros países. O nosso país é muito violênto. Ex. Pessoas que sequestra, brigam, roubam e etc.

Pessoas que não obedecem os sinais de trânsito. Famílias probes que não tem o que comer tem problemas em casa. (Texto II)

Os textos 5, 7, I I e 12 apresentaram somente este tipo de argumento factual geral; já em outros textos, é possível encontrar a presença dos três tipos de argumentos.

Os enunciados abaixo também foram identificados como referentes a argumentos do tipo factual geral, uma vez que as crianças fazem uso de uma narração para sustentar um enunciado-conclusão que antecede a narração (no caso do Texto I), ou que a precede (no caso do Texto 13). Essas narrações parecem ter sido baseadas em experiências e valores mais coletivos, uma vez que a criança não se coloca como participante da narrativa; desse modo, foram identificados como argumentos factuais gerais. Observe-se o exemplo do Texto 13:

Havia um menino que era muito mal então ele estava passando na rua quando um menino falou:....

Então o moleque começou a brigar, quando uma mulher passando pela rua viu.

Ela falou para eles:

- Ei menino parem de brigar, e aí eles pararam. E ai ela começou a contar uma longa estória.

- Era uma vez um menino que não tinha mãe e nem paí ele era barrigudinho...

Aí chegou um dia que ele foi pedir esmola por casas tão ricas.

Quando uma mulher the deu um tapa no rosto e o menino foi parar na guia quando bateu sua cabeça.

Ele foi parar no hospital e quando o médico foi ver ele estava morto jogado na cama.

A mulher que estava contando a história falou:

- Viu a violência entre os maiores e menores sempre acaba se dando mal.

Viu coleguinha a violencia não pode acontecer.

Evite a causa de violência... (Texto 13)

Os argumentos do tipo axiológico referem-se àqueles que exprimem, mais freqüentemente, um julgamento moral do locutor. Seguem alguns destes argumentos:

O que acontece é que maridos não tem muito amor em sua família.

E por isso quando tem muito problemas em sua casa, na rua ou em qualquer outro lugar. Desde então bebe muito e sua família que não tem nada há vê com isso que acaba levando as consequências. (Texto 6) 
Violência é um moral, por exemplo se alguém chingar sua mãe de filha duma puta você vai envocar com quem chingou.

Então não briguem porque você vai em mal caminho. (Texto |4)

Já os argumentos do tipo prescritivo referem-se à avaliação de uma obrigação pelo locutor. Estes argumentos apareceram uma única vez em cada um dos textos; seguem alguns exemplos:

A violência na rua é muito comum

Em todas as cidades e não é só criança que briga é também adultos, os adultos devia dar exemplos as crianças para não brigar. (Texto 8)

... A violência no trânsito é mais ou menos diferente, muitas pessoas bebadas ou até sem estar bebadas não respeitam a sinalazão ou as regras de trânsito

Essas pessoas defiam ser multadas ou até mesmo pressas. (Texto 6)

Como se pode observar, variou a natureza dos argumentos utilizados. Os argumentos do tipo factual geral e axiológicos foram os que mais apareceram nos textos, sendo que os do tipo prescritivo tiveram menor ocorrência. Não foi registrada a ocorrência de argumentos do tipo factual geral-particular.

Isso mostra, em geral, a habilidade das crianças dessa idade em se posicionarem diante de um determinado assunto e emitirem julgamentos de valor a partir de experiências mais coletivas para persuadir, no caso desta pesquisa, as crianças de outras escolas sobre o problema da violência.

\section{Os estágios de aquisição da capacidade argumentativa}

A tentativa de utilizar o discurso para modificar as representações ou opiniões de uma pessoa sobre um determinado assunto exige que o locutor coloque em prática certos processos textuais.

Cabe lembrar que, conforme Golder (1994, p. I87, trad. nossa), os dois processos mais importantes subjacentes à produção do texto argumentativo são: o processo de sustentação e o processo de negociação. A negociação argumentativa é o processo pelo qual os falantes "deslocam-se" de seu discurso e fornecem espaço para a discussão, envolvendo maneiras de o falante negociar com seu destinatário. A negociação trata de induzir o interlocutor a aderir às idéias do locutor por meio de explicações e do engajamento de afirmações próprias no seu discurso. Dessa forma, o processo de negociação argumentativa pode ser executado de várias maneiras, mas tanto em situações orais como em situações escritas, o que é mais freqüentemente observado, é o falante assumir uma posição com afirmações próprias e selecionar argumentos que lhe permitam negociar com seu destinatário e, assim, induzi-lo a assumir sua posição.

No caso dos textos em análise, não fica explícito o processo de negociação, 
certamente porque a criança (o falante ou locutor) não tem presente o seu destinatário para poder levar em consideração sua opinião e negociar com ele. No entanto, ainda segundo Golder (1994, p. I88, trad. nossa), o processo de negociação tem sido observado em crianças com pouca idade, em situações de diálogo, com um progresso crescente, tanto nestas situações como na escrita, até a adolescência.

Nesse nível de análise focalizaram-se as operações de sustentação utilizadas pelas crianças na organização da estrutura argumentativa. $\bigcirc$ objetivo principal foi identificar nos textos produzidos os estágios de aquisição da capacidade de argumentar das crianças, ou seja, a capacidade de construir um discurso no qual um enunciado-conclusão (EC) em que é explicitada uma posição apóia-se em enunciados argumentativos (EA).

Tais estágios foram sugeridos por Golder e Coirier (1993), a partir de pesquisas realizadas sobre a organização estrutural de textos escritos de crianças e adolescentes, na faixa etária de 7 a 16 anos, na França.

Os estágios de aquisição da capacidade argumentativa são três:

I. Pré-Argumentativo: neste estágio nenhuma posição é assumida, ou uma posição é assumida mas não é sustentada por qualquer argumento.

2. Argumentação mínima: ocorre a explicitação de uma posição que é sustentada por um só argumento.

3. Argumentação elaborada: ocorre a explicitação de uma posição que é sustentada por, pelo menos, dois argumentos.

Neste estudo, observou-se freqüentemente a presença de mais de um enunciadoconclusão que se apoiava em enunciados argumentativos num mesmo texto. Quanto à contagem do número de argumentos utilizados para sustentar um enunciado-conclusão, foi considerado um argumento quando a criança utilizou um grupo de argumentos de um mesmo tipo (factual, axiológio ou prescritivo) que se relacionam.

No estágio pré-argumentativo, foram identificados três textos, sendo que em todos houve uma tomada de posição não sustentada do locutor.

Seguem-se alguns dos enunciados dos textos que apresentaram tomadas de posição não sustentadas pelas crianças:

(EC) Então não briguem porque você vai em mal caminho. (Texto I4)

(EC) A violência é causada em varias cidades Paises e Estados.

(EC) Eles precisam mais de união compreenção para não roubar. (Texto 17)

Nos enunciados dos textos acima, observou-se que as crianças assumem uma posição por meio de um ou dois enunciados-conclusão; no entanto, ao longo do texto, elas não os sustentam, optando por desenvolver o texto explicando os tipos de violência (Texto 17).

No estágio de argumentação mínima, observou-se a presença de textos em que 
uma posição é assumida e sustentada por um só argumento. Deve-se ressaltar que os argumentos utilizados foram todos não autocentrados no locutor, isto é, a criança buscou basear seus argumentos em valores sociais mais coletivos para que fossem mais bem aceitos por seus interlocutores.

Sobre isso Shober e Clark (apud Golder, Coirier, 1993, p. 189) defendem que os argumentos, para serem aceitos, devem ser baseados em representações que são derivadas do conhecimento compartilhado entre os interlocutores (trad. nossa). Pode-se afirmar que as crianças que utilizam esse tipo de argumento não autocentrado estão em nível mais avançado que outras dentro desse mesmo estágio; no entanto, não foram observados nos textos pertencentes ao estágio argumentos centrados no locutor.

Seguem-se alguns dos enunciados-conclusão (EC) que apresentam o posicionamento das crianças apoiados em seus respectivos enunciados argumentativos, identificados em dez textos:

(EC) Em nosso País o nível de violêcia está crescendo.

(EA) Isso acontece geralmente com os filhos de familias ricas. Quando os Pais viajam para Europa Paris Roma etc. e deixam seus filhos com babas, colegios internos.

(EC) O número de violência não tem jeito de acabar mas sim diminuir...

(EA) ... exemplos. pensar antes de por um filho no mundo, etc

E devemos pensar antes de ter filhos com pessoas masculinas e fazer aborto, andar com boas companhias e pensar muito como: voltar tarde para casa, não andar sozinhos etc. (Texto 4)

(EC) A número de violência em nosso município vem aumentando cada vez mais com as rebeliões que acontecem nas grandes cidades.

(EA) Porque os fugitivos vêem para as cidades do interior. E nisso nossa cidade fica com grandes números de pessoas violentas. (Texto 5)

(EC) Em nosso país existe muitas violencias como em outros países. O nosso país é muito violênto.

EA) Ex: Pessoas que sequestra, brigam, roubam e etc. Os pais são preso por que falta furto em casas.

Pessoas que não obedecem os sinais de transito. Familias probes que não tem o que comer tem problemas em casa. Gente que mata e filhos vendem. E muitas outras coisas que acontece. (Texto II)

No Texto 4, ocorreu a presença de dois enunciados-conclusão (EC), sendo o primeiro enunciado-conclusão (ECI), sustentado por um argumento do tipo factual e o segundo enunciado-conclusão (EC2) sustentado por um argumento do tipo prescritivo. No Texto 5, o enunciado-conclusão foi sustentado por um argumento do tipo factual geral. $\bigcirc$ enunciado argumentativo do Texto II, conforme destacado, apresenta um grupo de argumentos do tipo factual considerados como um argumento, por se tratar de um mesmo tipo e a criança apenas tê-lo citado sem comentá-lo.

No estágio de argumentação elaborada, foi possível identificar quatro textos com a 
utilização de, no máximo, dois argumentos para cada enunciado-conclusão. Cabe salientar que os textos identificados nesse nível, embora apresentem mais de um argumento para sustentar uma posição, não representam um nível mais elaborado de argumentação; podese dizer que são textos em processo de construção de tal elaboração, dependendo parcialmente da estrutura cognitiva dessas crianças.

Conforme Golder (1994, p. 188, trad. nossa), a estrutura da argumentação elaborada do discurso escrito consiste num posicionamento sustentado por mais dois argumentos baseados em normas coletivas e relacionados por restrição, especificação, contra-argumentação, complementação etc., e esta estrutura não é adquirida até a idade de 15 ou 16 anos, segundo estudos realizados.

Seguem-se alguns dos enunciados dos textos identificados neste estágio:

(EC) para Nós a Violência é uma coisa muito serio...

(A I) eu acho que mais De I milhão de pessoas praticam esse tipos de Violência por, Ex: Violência, é briga de marido e mulher e estrupo de menores, o alcoolismo pode levar uma pessoa a Violência...

(EA 2) eu acho que isso tudo é falta de amor e irresponsabilidade, carinho e tudo mais.

Eu não gosto de uma Violência que e praticada pelos marido, mulheres matam filho.

Tudo isso é uma violência causada por pessoas que não tem sentimento. (Texto 3)

No Texto 3, ocorre a presença de um enunciado-conclusão (EC) que se apóia em dois argumentos, um do tipo factual (EA I) e outro formado por um grupo de argumentos axiológicos que, no caso desta pesquisa, está sendo considerado como um argumento, conforme já explicitado anteriormente.

(EC) A violência na rua é muito comum em todas as cidades...

(EA I)... e não é só criança que briga é também adultos, os adultos devia dar exemplos as crianças para não brigar.

(EA 2) No mundo a violencia acontece por que tem muito nervosismo e por causada pobresa no mundo.

A pobresa é a causa da violencia, dos roubos e dos açacinos eles matam robam e bate para ganhar dinheiro. (Texto 8)

No texto acima, verificou-se a presença de um enunciado-conclusão (EC) que se apóia em dois argumentos: um do tipo prescritivo (EA I) e outro do tipo factual (EA 2).

(EC) A violência em nosso país é muito grave por causa das drogas, maconha e do alcool etc.

(EA I) A violência só nos leva á agressão, maldade, ataqués constantis etc...

(EA 2) Os meninos que são abandonados ou os meninos de rua é o alvo do violência porque saem das escolas para usar drogas e os outros tipos de drogas como o alcool. (Texto I0)

No texto 10, observou-se a presença de dois argumentos do tipo factual para apoiar o enunciado-conclusão (EC). 
Em síntese, os textos produzidos distribuíram-se entre os três estágios de aquisição da capacidade argumentativa da seguinte maneira: dos 17 textos analisados, 18\% (3 textos) foram classificados no estágio pré-argumentativo, 59\% ( 10 textos), no estágio de argumentação mínima e 23\% (4 textos), no estágio de argumentação elaborada, considerando-se, obviamente, as ressalvas feitas quanto ao enquadramento dos textos neste último estágio.

Tais resultados demonstrados pelas crianças foram animadores, considerando-se o recente contato delas com esse tipo de discurso escrito e a maioria delas (82\%, 14 textos) ter sido capaz de sustentar uma posição assumida com o uso de, pelo menos, um argumento.

\section{O desenvolvimento da habilidade de argumentar}

Nos textos de algumas crianças, foi possível observar um progresso na habilidade de argumentação, ao se comparar a primeira produção escrita com a terceira de cada uma delas; assim, buscou-se identificar em relação a que pontos ocorreu tal progresso.

O aspecto escolhido para demonstrar o progresso dessas crianças na habilidade de argumentação foi identificar a capacidade de elas se posicionarem sobre o assunto pela elaboração de um enunciado-conclusão e sustentá-lo, utilizando-se de enunciados argumentativos.

A seguir os textos analisados de uma das crianças:

\section{CRIANÇA I \\ ( -10 anos $-4^{\mathrm{a}}$ série)

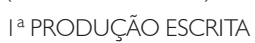 \\ As crianças abandonadas do Brasil.}

Crianças abandonadas são meninos de rua.

As que os pais não têm como tratar dos filhos.

As que á família não têm amor.

As crianças abandonados, quando sentem fome e não têm comida roubam ou também quando têm vontade de comprar algo.

(EC) [O Brasil está cheio de crianças abandonadas.]

(EA) [O problema é que pouca gente ajuda, os ricos querem cada vez ficar mais rico e nem ligam para os pobres.]

No Brasil tem muita gente pobre.

Quanto à I ${ }^{a}$ produção escrita da Criançal, foi possível identificar um enunciadoconclusão, conforme destacado no texto, no qual a criança afirma que "O Brasil está cheio de crianças abandonadas". Neste caso, a criança elabora um enunciado argumentativo para sustentar tal afirmação com um argumento que apresenta uma justificativa para o problema da pobreza no país. 


\section{2a PRODUÇÃO ESCRITA \\ Os problemas do álcool externo e interno.}

(EC) [O álcool é um problema para quem bebe e para quem tem amigos e familiares que bebem.]

(EA I) [O problema de quem bebe é interno, pois o álcool nos destrói o fígado, destrói as nossas celulas e muito mais.]

(EA 2) [O problema de quem tem amigos e familiares que bebem é externo porque os bêbados brigam com pessoas e familiares sem razão, batem nos filhos e mulheres, etc.

O álcool também nos traz a doença chamada Cirrose.

O álcool rende milhões para quem faz e mata muitos alcoolótras no mundo inteiro.] (EA 3) [Tem gente que bebe para esquecer os problemas, mas depois no outro dia esta com muita dor de cabeça e o problema não sumiu.

Por isso e por muitas outras coisas não devemos beber bebidas com álcool.]

Na segunda produção escrita, identificou-se a presença de um enunciado conclusivo no qual a criança afirma que o álcool é um problema para o alcoólatra e para quem convive com ele. Para sustentar essa afirmação, ela utiliza-se de três enunciados argumentativos: dois para explicar as conseqüências à saúde da pessoa (EA | e 3) e outro (EA 2) para explicar as conseqüências sociais do alcoolismo, conseguindo sustentar bem seu posicionamento.

\section{3a PRODUÇÃO ESCRITA \\ A Violência}

(EC) [No mundo inteiro existem muita violência tanto física como moral.]

(EA) [A maioria das violências são causadas pela droga e o álcool.

Mortalidade infantil, aborto, exploração do trabalho infantil, estrupos e acidentes de trânsito tambêm são violências.]

No futebol existe muita violência entre as torcidas organizadas.

Alguns policiais praticam violência contra os presos.

Nas cadeias existe violência entre os presos por causa dos estrupadores.

(EC) [A cidade de Mogi Guaçu esta a cada dia mais violenta.]

(EA) [A delegacia de mulher de Mogi Guaçu recebe 20 chamadas por noite.

As crianças não devem ficar até muito tarde sozinhas e devem evitar shorts curtos.]

Já na terceira produção escrita, observou-se a presença de dois enunciados-conclusão diferentes, que se apóiam em dois enunciados argumentativos diferentes. Tais argumentos basearam-se em fatos ocorridos na comunidade e em informações obtidas e debatidas com os colegas e adultos durante o procedimento desenvolvido.

Comparando-se a primeira produção escrita com a terceira produção da criança, observou-se um avanço da habilidade de argumentar: na primeira produção, ela apenas 
justifica superficialmente seu posicionamento, enquanto, na segunda produção, ela chega a sustentar uma posição com dois argumentos; finalmente, na terceira produção escrita, a criança apresenta dois enunciados-conclusão que se apóiam em dois enunciados argumentativos.

Tal evolução foi observada na capacidade desta e das outras crianças em construir enunciados conclusivos, explicitando um posicionamento sobre o assunto e sustentando tal posicionamento através de justificativas, comentários, exemplos etc.

Cabe explicitar que, com relação à presença da primeira pessoa do plural nos textos de três crianças, tal uso é indicador da intenção do locutor de persuadir seu interlocutor, procurando compartilhar o problema em discussão com o interlocutor - neste caso, uma criança de outra escola da cidade - e com isso obter maiores chances de persuadi-la.

Deve-se, também, ressaltar o aumento generalizado observado na extensão dos textos a partir da segunda produção escrita, ao comparar com os textos da primeira produção escrita. Tal aumento foi representado pela ampliação do número de palavras, verbos e organizadores textuais, refletindo um maior cuidado das crianças na elaboração de seus textos ao ter que organizá-los com um número maior de informações e opiniões.

\section{CONCLUSÕES}

A análise dos textos obtidos pelos procedimentos adotados demonstra a riqueza com que as crianças de $4^{\mathrm{a}}$ série de uma escola pública de periferia construíram textos dissertativos.

Recentes pesquisas sobre a aquisição do discurso, citadas por Dolz (mimeo), mostram que não existe uma progressão da aprendizagem relativa à língua escrita entre os gêneros narrativo, descritivo e dissertativivo, como se acredita em nosso meio escolar. Ainda se encontra essa falsa concepção sustentando a estrutura curricular do ensino da Língua Portuguesa.

Tal perspectiva tradicional considera que a aprendizagem das formas discursivas da explicação e da argumentação é mais complexa e aparece relativamente mais tarde, necessitando da base proporcionada pelo gênero narrativo para se desenvolver - o que vem sendo questionado, inclusive por esta pesquisa. Isto porque, conforme os vários autores já citados, a narração, a descrição e a argumentação são modalidades diferentes de discurso que abrangem elementos particulares e requerem um aprendizado específico.

No caso da dissertação, o que a diferencia dos outros gêneros discursivos são: a situação de comunicação na qual é produzida, as operações que requer do locutor, as articulações dos argumentos com o intuito de servir a uma intenção, as numerosas formas expressivas e propriedades lingüísticas que são associadas dominantemente a ela e algumas características superestruturais específicas.

Desta forma, tudo indica que a aquisição desse tipo de discurso escrito ocorre mais 
tardiamente, não pela sua complexidade, mas porque a escola não tem proporcionado, sistematicamente, situações para as crianças exercitarem o texto dissertativo.

É importante também citar a ausência de textos dissertativos na literatura infantil e nos livros didáticos que envolvam a exposição de um ponto de vista do autor sobre uma questão particular, numa dimensão dialógica, ou que envolva a sustentação de uma posição com mais de um argumento, incluindo a contra-argumentação.

Pode-se, portanto, afirmar que as crianças são capazes de elaborar textos dissertativos desde que lhes sejam proporcionadas condições pedagógicas favoráveis.

Neste estudo, algumas condições pedagógicas desenvolvidas no procedimento utilizado podem ser consideradas fundamentais, como facilitadores do processo de produção de textos dissertativos pelas crianças:

- contato com diferentes textos dissertativos, pela leitura;

- exercício de elaboração escrita deste tipo de texto;

- acesso a informações variadas sobre o tema, por meio dos grupos de estudo e da relação dialógica entre alunos, aluno-professor, aluno-profissionais, na troca e no confronto de idéias em situações de entrevistas e debate coletivo;

- tema em estudo ter sido escolhido a partir de uma discussão sobre um problema do cotidiano da comunidade em que vivem;

- atender a uma finalidade social, ou seja, tentar conscientizar as crianças de outras escolas quanto às causas, conseqüências e prevenções do problema em questão.

Tais condições possibilitaram aos alunos confrontarem essa modalidade de texto com as que já conheciam e buscarem compreender as estratégias e situações de argumentação. $\bigcirc$ exercício da elaboração escrita possibilita o aprimoramento gradativo da criança neste e em qualquer tipo de texto.

Por outro lado, a relação dialógica estabelecida entre os alunos, o professor e os profissionais entrevistados, com troca de informações e confronto de opiniões na sala de aula, sem dúvida, possibilitou à maioria das crianças condições para uma tomada de posição mais crítica sobre o assunto.

Conforme mostram os estudos sobre os processos de aquisição, a linguagem não é apenas um elemento da cognição; ela exerce o papel de atividade constitutiva do próprio pensamento (Lopes, 1992, p. I).

A importância da relação dialógica entre as crianças e os adultos fica clara ao se observar que os argumentos construídos por elas, em geral, demostraram as compreensões e os julgamentos que fizeram das informações recebidas, somadas às suas experiências cotidianas. 
Semelhantes às relações observadas nesta pesquisa, Dolz (mimeo, p. 5) destaca as seguintes situações para o aprimoramento do ensino da habilidade de argumentar:

- contato com situações argumentativas e com textos argumentativos contrastados;

- treino de elaboração de diferentes argumentos e contra-argumentos e organização destes argumentos em um plano de texto;

- a iniciação de situações verbais e escritas de colaboração que facilitam a aprendizagem da negociação, e a prática de certas estratégias específicas da argumentação.

A partir dos dados observados nesta pesquisa, resta a emergência de que mais estudos sejam realizados no sentido de levar à escola e aos planejadores do ensino maiores conhecimentos sobre a estrutura textual e as funções sociais do texto dissertativo na Língua Portuguesa. A questão que se coloca não é questionar se a criança em tal idade está preparada ou não para escrever um texto dissertativo, mas proporcionar-lhe oportunidades e condições favoráveis para que ela desenvolva adequadamente sua produção escrita.

A introdução ao texto dissertativo nas séries iniciais do $1^{\circ}$ grau, além de proporcionar mais chances de sucesso aos alunos na produção dessa modalidade de texto ao término do $2^{\circ}$ grau, certamente facilitará o desenvolvimento de uma postura crítica, que possibilite aos alunos refletir sobre a realidade social onde vivem.

Talvez o desenvolvimento da habilidade de argumentar seja um dos caminhos para se resgatar a opção política de incentivar a criticidade nos alunos, partindo-se da linguagem e do estudo de conteúdos relacionados com a realidade social destes sem, no entanto, desmerecer os outros tipos de texto.

\section{REFERÊNCIAS BIBLIOGRÁFICAS}

BANKS-LEITE, L. Aspectos argumentativos e polifônicos da linguagem da criança em idade pré-escolar. Campinas, 1996. Tese (dout.) UNICAMP/IEL.

DOLZ, J. Learning argumentative capacities: a study of the effects of a systematic and intensive teaching of argumentative discourse in $11-12$ year old children. Geneva, mimeo.

GOLDER, C. Argumentative text writing: developmental trends. Discourse Processes, n. 19 , p.187-210, 1994.

GOLDER, C., COIRIER P. Savez vous argumenter à la mode... à la mode des petits? Enfance, France, v.47, n.4, p.359-76, 1993.

GRIZE, J.B. Pour aborder letude des structures du discours quotidien langue française, n.50. Paris: Larrousse, 1981. 
KOCH, I.V.G. Argumentação e linguagem. 2.ed. São Paulo: Cortez, 1987.

A Coesão textual. 6.ed. São Paulo: Contexto, 1993.

LEMOS, C.T.G. Interacionismo e aquisição da linguagem. Delta, v.2, n.2, p.23। -48, 1986.

LOPES, T.M. A Construção de definições por crianças. Campinas, 1992. Dissert. (mestr.) UNICAMP/IEL

LÜDKE, M.; ANDRÉ, M.E.D. A Pesquisa em educação: abordagens qualitativas. São Paulo: EPU, 1986.

MARTINEZ, R.H.B. Subsídio curricular de língua portuguesa para o $1^{\circ}$ e $2^{\circ}$ graus. São Paulo: CENP, 1988. V.3: Três tipos de discurso.

OSAKABE, A. Redações no vestibular: provas de argumentação. Cadernos de Pesquisa, São Paulo, no. 23, p.5I-9, 1977.

PETRONI, M.R. A Organização do texto escrito por alunos do $1{ }^{\circ}$ grau. Campinas, 1994. Dissert. (mestr.) UNICAMP/IEL.

SÃO PAULO (Estado). Secretaria da Educação: Coordenadoria de Estudos e Normas Pedagógicas. Proposta curricular para o ensino de língua portuguesa: 10 Grau. 4.ed., São Paulo, 1992.

\section{ANEXO ।}

Os textos abaixo compõem a terceira produção escrita e foram transcritos respeitando-se a organização textual de cada aluno, bem como o padrão ortográfico.

\section{Texto 1}

\section{A viôlencia no nosso Países}

Antigamente no Brasil não existia muitas viôlencia mas hoje em I.995 existe muitas violencias. Por exemplo drogas, brigas, mortes etc...

E também não acaba isto, mas diminuir sim.

Mas como as policias vom agüentar isto?

A a cadeia não resorve.

Se ficar soltos mata não tem condições.

Eu vou falar um hestória para vocês.

Era uma vez um homem que estava solto da cadeia e estava estrupando todas as meninas.

Mas chegou um dia que uma menina passou perto dele que ela estava com shortes bem curto e o homem parou ela e falou:

- Menina você quer ir passear com migo. Ela falou:

- Você está ficando louco? 
- Eu não vou sair com você.

Mas ai ela saiu correndo e ele foi atráz

Ela gritou:

- Socorro me ajuda.

A policia chegou rapido e ele foi preso ela foi libertada.

E ela nunca viu mais o homem.

(LI, 4a série, 10 anos)

\section{Texto 2}

\section{$\underline{\text { A Violencia }}$}

A pessoa quando comete uma violencia a pessoa deve esta abandonada, drogada bebada. Ou então a pessoua que foi agredida talvez esta devendo alguma para a outra ou então tinha feito alguma coisa de erada para outra pesoa. Mas se as pessoas estão esperando que o governo fara alguma coisa estão enganados nos mesmos temos que colaborar para acabar com a violência. Muitos presos na delegacia agride os outros por que não obedeceu o chefe da cadeia la na cadeia cada um tem um religião.

E quando entra um preso que tem uma religião deferente que eles não gostam eles agride com uma violencia fisíca que pode ate causar a morte.

(V, $4^{\mathrm{a}}$ série, 10 anos)

\section{Texto 3}

\section{As Violência}

A violência é uma pessoa ignorar outra pessoa.

para Nós a Violência é uma coisa muito serio, eu acho que mais De I milhão de pessoas praticam esse tipos de Violência por,

Ex: Violência, é briga de marida e mulher e estrupo de menores, o alcoolismo pode levar uma pessoa a Violência. eu acho que isso tudo é falta de amor e irresponsabilidade, carinho e tudo mais.

Eu não gosto de uma Violência que e praticada pelos marido, mulheres matam filho.

Tudo isso é uma violência causada por pessoas que não tem sentimento.

(AL, $4^{a}$ série, II anos)

\section{Texto 4}

\section{A violência em nosso País}

Em nosso País o nivel de violêcia está crescendo. Falta de comprienção (com os pais) na casa dos pais.

Isso acontece geralmente com os filhos de familias ricas. Quando os Pais viajam para Europa Paris, Roma etc. e deixam seus filhos com babas, colegios internos.

Outro tipo de violência é quando marido espanca mulher e filhos estrupam filhas, etc.

O numero de violência não tem jeito de acabar mas sim diminuir, por exemplos. pensar antes antes de por um filho no mundo, etc. 
E devemos pensar antes de ter filhos com pessoas masculinas $\underline{e}$ fazer aborto, andar com boas companhias e pensar muito como: voltar tarde para casa, não andar sozinhos etc.

( $M, 4^{\mathrm{a}}$ série, 10 anos)

\section{Texto 5}

\section{A violência}

Violência é todo tipo de agressão fízica ou morral.

Violência física é todo tipo de violência de agressão de uma pessoa contra a outra.

Violência morral é todo tipo de violencia como chingos e palavroes, isso parese não ser um violência, mas todos aceitãm palavrões como uma grande violência.

A número de violência em nosso município vem aumentando cada vez mais com as rebeliões que acontecem nas grandes cidades.

Porque os fugitivos vêem para as cidades do interior. É nisso nossa cidade fica com grandes números de pessoas violentas.

Em Campinas houve uma briga entre jogadores de futebol e um rapaz de 16 anos pulou no quintal de outro rapaz de 17 anos. E dai foi quando o rapaz mais velho deu 4 tiros no peito do rapaz de 16 anos.

Depois de ter feito a ocorencia o rapaz de 17 anos falou que ele tinha matado o outro rapaz e com os seus 18 anos ele não poderia matalo porque senão ele iria preso pelomenos por uns 10 a 15 anos detido na prisão.

Ele praticou o violência fisica matando o outro rapaz com tiros.

(A, $4^{\mathrm{a}}$ série, 10 anos)

\section{Texto 6}

Texto sobre a violência

A violência é estrupos, acidentes, marido que espanca mulher e filhos. Ea violência é mais acontecida em $S$.Paulo e outras cidades grandes $O$ que acontece é que maridos não tem muito amor em sua familia $\underline{E}$ por isso quando tem muito problemas em sua casa, na rua ou em qualquer outro lugar. Desde então bebe muito e sua familia que não tem nada há vê com isso que acaba levando as consequências. A violência no trânsito é mais ou menos diferente, muitas pessoas bebadas ou até sem estar bebadas não respeitam a sinalazão ou as regras de trânsito Essas pessoas defiam ser multadas ou até mesmo pressas. A cidade de M. Guaçu é a $3^{a}$ cidade que tem mais violência. Se nos pudessemos acabar ou diminuir com a violência as cidade seria mais calma.

(LA, $4^{\mathrm{a}}$ série - 10 anos)

\section{Texto 7}

\section{A violencia no país}

A violencia não ocorre ș na nossa região e sim no pais inteiro

Violencia não é só corporal é tambem moral

Corporal ocorre quando uma pessoa se agride com a outra, matão uns aos outros matão uns 
aos outros, e violencia moral é quando uma pessoa chama sua mãe de puta ou mesmo de galinha

Se uma pessoa estrupa a outra é uma violencia, manter pessoas como refem e violencia assaltos, rachas, roubos etc

Principalmente trombadinha

Acabar com a violencia é impossivil a policia tenta mas não consegue.

(EL, $4^{\mathrm{a}}$ série, 10 anos)

\section{Texto 8}

A Violência na rua nas casas e nas cadeias

A violência na rua é muito comum

Em todas as cidades e não é só criança que briga é também adultos, os adultos devia dar exemplos as crianças para não brigar.

A violência nas casas é que a mãe bate nos filhos só por causa que os filhos não querem sair da para trabalhar, e também existe outro tipo é o marido bater na mulher na mulher por causa da bebida ou das drogas.

A violência na cadeia é quando os policiais batem nos presos ou os presos batem nos outros presos.

No mundo a violencia acontece por que tem muito nervosismo e por causa da pobresa no mundo.

A pobresa é a causa da violencia, dos roubos e dos açacinos eles matam, robam e bate para ganhar dinheiro.

(E, $4^{\mathrm{a}}$ série, 10 anos)

\section{Texto 9}

A Violência

No mundo inteiro existem muita violência tanto física como moral.

A maioria das violências são causadas pela droga e o álcool.

Mortalidade infantil, aborto, exploração do trabalho infantil, estrupos e acidentes de trânsito tambêm são violências.

No futebol existe muita violência entre as torcidas organizadas.

Alguns policiais praticam violência contra os presos.

Nas cadeias existe violência entre os presos por causa dos estrupadores.

A cidade de Mogi Guaçu esta a cada dia mais violenta.

A delegacia de mulher de Mogi Guaçu recebe 20 chamadas por noite.

As crianças não devem ficar até muito tarde sozinhas e devem evitar shorts curtos.

(I, $4^{\text {a }}$ série, 10 anos $)$

\section{Texto 10}

A violência

A violêcia em nosso país é muito grave por causa das drogas, maconha e do alcool etc. 
A violência só nos leva á agressão, maldade, ataqués constantis etc...

Os meninos que são abandonado ou os meninos de rua é o alvo da violência porque saem das escolas para usar drogas e os outros tipos de drogas como o alcool.

que nos leva a violência:

O que nos leve a violêcia é as BEBIDA como alcool.

O que a gente podemos fazer para acabar com a violencia em nosso país?

(JO, $4^{\mathrm{a}}$ série, 10 anos)

\section{Texto II}

$\underline{\text { Oque é Violência }}$

A violência é quando os pais brigam com os filhos, porque está com algum problema no trabaIho, em casa e algum lugar.

Em nosso país existe muitas violencias como em outros países. $\bigcirc$ nosso país é muito violênto. Ex: Pessoas que sequestra, brigam, roubam e etc. Os pais são preso por que falta furto em casas. Pessoas que não obedecem os sinais de transito. Familias probes que não tem o que comer tem problemas em casa. Gente que mata e filhos vendem. E muitas outras coisas que acontece.

( $R, 4^{\mathrm{a}}$ série, 10 anos)

\section{Texto 12}

\section{$\underline{\text { A violência }}$}

Em nossos país existem muitas pessoas que Brigam isso é Violência.

Brigas entre mulheres e homens, e desempregado.

Muitas violências estão acontecendo em nossos país.

A violências causa muito problemas em nossas familias na mãe, no pai, e até nos filhos e nas filhas.

Violência é quem matam, robam as coisas das pessoas.

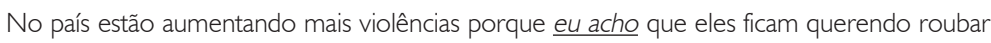
moveis e outros ficam brigando por causa de encher o saco dos outros ou porque querem Brigar.

( $M A, 4^{a}$ série, 10 anos)

[Observação: A criança acima não participou do processo de estudo que antecedeu a produção escrita.]

\section{Texto 13}

O meninos de Rua com a sua violência

Havia um menino que era muito mal então ele estava passando na rua quando um menino falou:

- Ei você ai, vem aqui. O que você quer, não me fale assim.

Você vai querer brigar?

- Vou sim por que?

Então o moleque começou a brigar, quando uma mulher passando pela rua viu.

Ela falou para eles: 
- Ei menino parem de brigar, e aí eles pararam. E aí ela começou a contar uma longa estória. - Era uma vez um menino que não tinha mãe e nem paí ele era barrigudinho mas seus braços era, bem fininhos e suas pernas só tinham ossos coitadinho. Era pobrezinho não tinha roupa o que ele vestia era uma folha de bananeira para cobrir suas pernas e não vestia camisa nenhuma. Aí chegou um dia que ele foi pedir esmola por casas tão ricas.

Quando uma mulher Ihe deu um tapa no rosto e o menino foi parar na guia quando bateu sua cabeça.

Ele foi parar no hospital e quando o médico foi ver ele estava morto jogado na cama.

A mulher que estava contando a história falou:

- Viu a violência entre os maiores e menores sempre acaba se dando mal.

Viu coleguinha a violencia não pode acontecer.

Evite a causa de violência.

A violencia na minha opinião é as pessoas que brigam ou se matam e etc.

Para você não causar a violência você tem que ser calmo relaxado quando estiver com raiva.

A violência é causada por brigas, chingos, matadores e etc.

( $K, 4^{\mathrm{a}}$ série, 10 anos)

\section{Texto 14}

Violência

Violência é um moral, por exemplo se alguém chingar sua mãe de filha duma puta você vai envocar com quem chingou.

Então não briguem porque você vai em mal caminho.

Um dia um homem bebeu pinga e queria me bater e ai eu fique quieto no meu lugar meu pai falou se alguém mexer comigo é para mim chamar ele

O homem que queria bater em mim ele deve ser castigado na cadeia.

E eu fiquei feliz.

(F, 4a série, 10 anos)

\section{Texto 15}

A violência

A violência é muito importante para prestar atenção quando você está nervoso, e acaba batendo em mulheres e filhos.

E a pessoa, acabam vender drogas para sustentar sua familias.

Exemplos:

- Primeiro lugar as crianças e as pessoas devem andar sempre com um grupos.

- Segundo lugar as Pessoas não dar bola para estranhos e ai po diante.

e também não aceitar balas e chiclete porque eles devem colocar maconha e outros objetos.

E também as pessoas venham pedir dinheiro e comidas não dá porque pessoas mitem a ser pessoas pobres mas não é, capaz de ser Rica.

E não deixa te tapear por isso em vite a violência contra as pessoas.

(JUA, 4a série, I lanos) 


\section{Texto 16}

Uma violencia Pode ser moral, ou fisica.

A moral é quando você ou eu agride uma pessoa como chinga e falar palavrão.

E a fisica e quando uma pessoa Bate na outra.

Muitas pessoas morrem, por coisa das Brigas.

A briga com os casais pode até ter assacinato ou estrupo com a propria mulher ou crianças Isso é muito ruim para os policiais tem que prender pessoas inosente ou culpadas. A violencia na minha opinião é que diminui com o robos é os ricos darem comida Para os probes assim vai diminuir a violência de torcedores e etec.

(JUO, $4^{\mathrm{a}}$ série, 10 anos)

[Observação: A criança não deu um título ao texto.]

\section{Texto 17}

A Violência do País

A Violência e um abordo, e abandono de mulheres e crianças, roubos, estrupos, e etc.

A Violência é causada em varias cidades Paises e Estados.

O abordo é como estrupos só que é com crianças e estrupos e com os dois também mas mais adultos.

Os roubos é ladroes que rouba por exemplo Lojas, Casas, Escolas, Dinheiros, mercados, etc. Eles precisam mais de união compreenção para não roubar. Hoje policias não estão nem consguindo pegar ladrões.

A Violência está demais.

O que será que vamos consciguir isto parar.

Não adianta nada nem cadeia?

(MR, $4^{\mathrm{a}}$ série, 10 anos) 